\title{
Effect of the Composition Ratio Against the Electrical Conductivity Properties and the Wear Rate of the Composite
}

\author{
Agus Edy Pramono \\ Mechanical Engineering Department, Politeknik Negeri Jakarta, Kampus UI, Depok 16425, West Java, Indonesia
}

Received: September 17, 2013 / Accepted: October 10, 2013 / Published: November 25, 2013.

\begin{abstract}
This article reveals the wear rate and electrical conductivity of composites made of carbon powder and waste of glass bottle with a phenolic resin matrix. The study was initiated with a carbonization of coconut shell, pulverized and filtered the carbon and waste glass bottles to reach the mesh size of $\geq 300$. Both materials were mixed with a composition ratio of carbon: glass, 70\%:30\%; 80\%:20\%; and 90\%:10\% weight. The mixture was mixed with phenolic resin adhesive and compacted with a load of 5 US ton. Results showed, the higher the carbon content, resulting in the higher the electrical conductivity, but also showed the lighter composite. Increased content of carbon powder made lighter composite, it also made the softer composite, so that the higher wear rate. Lowest wear rate was showed by a mixture of carbon-glass composite with a composition ratio of 70:30, which was $6.86738 \mathrm{E}-06 \mathrm{~mm}^{3} / \mathrm{Nm}$. Carbon powder was softer than glass powder, the highest rate was indicated by the carbon-glass composite with 90:10 composition, which was $8.67425 \mathrm{E}-06 \mathrm{~mm}^{3} / \mathrm{Nm}$. A high content of carbon powder encouraged an increase electrical conductivity of the composite. Mixture of carbon-glass composite with the composition ratio of 90:10 produced electrical conductivity of $0.192 \mathrm{~S} / \mathrm{m}$.
\end{abstract}

Key words: Wear rate, electrical conductivity, carbon-glass composite, coconut shell waste, glass waste.

\section{Introduction}

In operation of electric rail vehicles, one of the components that must be considered is the collector strip on the pantograph and catenary with friction contact with power lines on top of the train. This is important because these materials will wear out, but it also must be able to conduct electricity [1]. This study was based on engineered composite of carbon powder of coconut shell and glass waste powder with phenolic resin as the adhesive matrix, as an alternative material of collector strip of pantograph. Friction and wear-resistant properties have been tested against a composite material made of carbon granulate with coal tar pitch as a matrix, this

Corresponding author: Agus Edy Pramono, doctor, associate professor, research field: composites. E-mail: aepram@yahoo.com. composite produced the lowest wear rate of 1.3 $\mathrm{mg} \cdot \mathrm{min}^{-1}$ and a maximum of $20.3 \mathrm{mg} \cdot \mathrm{min}^{-1}$ [2]. Tangle of long fibers of carbon from PAN soaked in adhesive mixtures containing nano particles of $\mathrm{TiO}_{2}$, $\mathrm{CaCO}_{3}$ and $\mathrm{SiO}_{2}$, resulting in wear rate decreased, compared to the composite of woven carbon fiber only [3]. Polyamide carbon fiber-reinforced composites has been studied, the composite produced wear rate of $2-4 \times 10^{-6} \mathrm{~mm}^{3} / \mathrm{Nm}$ [4]. PAN-based carbon fibers were used as reinforcement fibers in carbon-carbon composites with matrix of pitch produced wear rate of 1 to $2.5 \mu \mathrm{m} / \mathrm{s} / \mathrm{f}$ [5]. Wear-resistant carbon-carbon composite material was ever made of carbon powder of coal waste with coal tar pitch matrix, the hot press process, the composite produced the lowest wear rate is $0.00087\left(10^{-7}\right.$ $\mathrm{mm}^{2} / \mathrm{kg}$ ) [6]. Engineering composites of carbon 


\section{Composite}

powder with matrix of waste glass powder has been carried out and showed that the composites made from powder of mesh size 100 produced wear rate of 2.77901E-05 mm $3 / \mathrm{Nm}$, while composites made from powder of mesh size 250 produced wear rate of $1.01562 \mathrm{E}-05 \mathrm{~mm}^{3} / \mathrm{Nm}$ [7]. Research on the electrical conductivity of carbon-carbon composites have been made. Results of this study demonstrated the greater density increased electrical conductivity of the composite. Highest electrical conductivity was $3.40 \mathrm{~S} / \mathrm{m}$ generated by the composite with $2 \mathrm{~g} / \mathrm{cm}^{3}$ density [8].

\section{Experiments}

\subsection{Preparation of Materials}

This work was started with the carbonization of coconut shell waste in the process of pyrolysis at temperatures of $900{ }^{\circ} \mathrm{C}$. Coconut shell carbon was ground in the disc/ball mill machine. The carbon powder of coconut shell waste was sifted to obtain the powder size of $\geq 300$ mesh, sieving was carried out in vibration filter machine. Glass bottles finely milled and sieved to obtain powder mesh sizes of $\geq 300$.

\subsection{Fabrication of Composite Samples}

Carbon powder of mesh size of $\geq 300$ was weighted by the weight percentage of $70 \%, 80 \%$ weight; and $90 \%$ weight. Glass powder of mesh size of $\geq 300$ was weighted by the percentage of $30 \%$ weight; $20 \%$ weight; and $10 \%$ weight. Carbon powder and glass powder of the proportion 70\%:30\% weight; 80:20 weight $\%$, and $90 \%: 10 \%$ weight evenly was mixed in a ball mill machine, then each composition was mixed with phenolic resin as the adhesive matrix. Next, the mixture was printed in the mold while holding with a load of 5 US ton. Sample pre-form sized $40 \mathrm{~mm}$ diameter and $15 \mathrm{~mm}$ thick.

\subsection{Flow Diagram of Experiment}

This work was carried out by following the flow chart shown in Fig. 1.

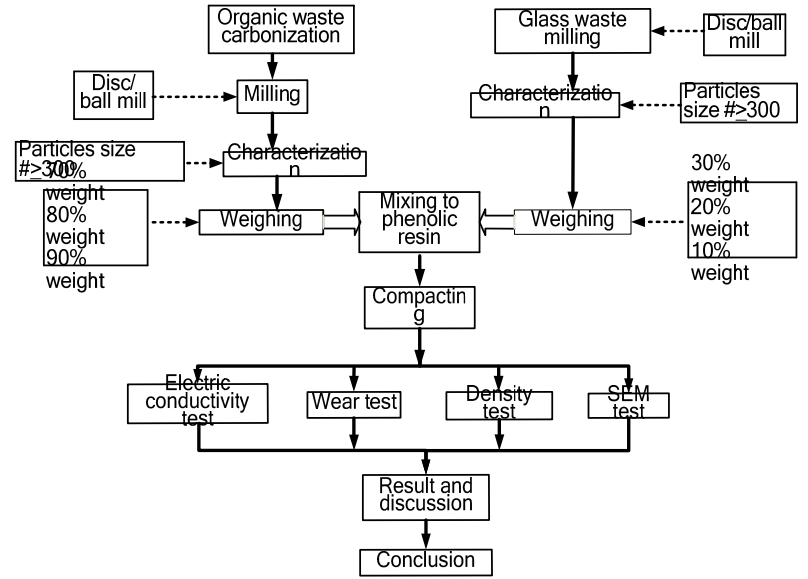

Fig. 1 Flowchart of research.

\subsection{Wear Testing}

Wear rate was tested with wear test machine by placing the test sample radially on the disc wear tester [9], then calculated by the following equation [7]:

$$
w_{\text {rate }}=\frac{B}{L . P}\left[\frac{\pi \cdot r^{2}}{180} \arcsin \left(\frac{b}{2 . r}\right)-\frac{1}{2} \cdot b(r-h)\right] \text { (1) }
$$

where, $b$ length of worn footprint in $\mathrm{mm}, L$ length of distance $\mathrm{m}, P$ workload in $\mathrm{N}, r$ radius of disc friction in $\mathrm{mm}, B$ wear-trace width in $\mathrm{mm}, h$ depth of wear tracks in $\mathrm{mm}$.

\subsection{Density of the Material}

Apparent density of carbon was measured by Archimedes method, by following the ASTM D 2862 standard. Apparent density of the glass was measured by following the standard ASTM C 729. Apparent density of the carbon and glass powder mixture is calculated by law of mixture, in appropriate composition ratio. Bulk density carbon-glass composite was tested by following the ASTM D792 standard. Apparent density testing for each ingredient and mix in powder form are shown in Table 1.

Table 1 Apparent density of carbon, glass, mixed.

\begin{tabular}{llll}
\hline $\begin{array}{l}\text { Carbon } \\
\left(\mathrm{g} / \mathrm{cm}^{3}\right)\end{array}$ & $\begin{array}{l}\text { Glass } \\
\left(\mathrm{g} / \mathrm{cm}^{3}\right)\end{array}$ & $\begin{array}{l}\text { Ratio } \\
\text { Composition }\end{array}$ & $\begin{array}{l}\text { Mixture density } \\
\left(\mathrm{g} / \mathrm{cm}^{3}\right)\end{array}$ \\
\hline & & $70: 30$ & 1.73418 \\
1.3794 & 2.562 & $80: 20$ & 1.61592 \\
& & $90: 10$ & 1.49766 \\
\hline
\end{tabular}




\subsection{Testing of Electrical Conductivity}

Measurements were performed to electrical resistance, the electrical current flow distance and cross-sectional area where the electrical current flowing in the composite, with a two-point probe method. Further the resistance static or $\rho$ is calculated by the following equation [8]:

$$
\rho=\frac{R . A}{l}[\Omega . \mathrm{m}]
$$

where, $\rho$ is static resistance in $\Omega \mathrm{m}, R$ is the electrical resistance in $\Omega$, A cross-sectional area in $\mathrm{m}^{2}, l$ length of distance of the current flows in $\mathrm{m}$. The electrical conductivity of the composite was determined by the following equation:

$$
\sigma=\frac{1}{\rho}[1 / \Omega m] \text { or with unit }[S / m\rfloor
$$

\section{7 SEM EDS Testing and Mapping}

The test was performed with a SEM testing machine of JEOL JSM - 6390A. Purpose of the test was to look at the microstructure of the composite carbon and glass powder. To see the possibility of the formation of voids in the composite. While the mapping were used to view the distribution homogeneity of the mixture and distribution of chemical elements that make up the bulk composite.

\section{Results and Discussion}

3.1 Relationships of the Electrical Conductivity to the Density of Carbon-Glass Composite

Electrical conductivity testing was conducted by two point probe method. Electrical conductivity calculation results showed that the greater the weight percentage of coconut shell carbon, the higher the electrical conductivity of the composite. As shown in Fig. 2. On the composition ratio of $90: 10$ produced electrical conductivity of $0.192 \mathrm{~S} / \mathrm{m}$, while for the $70: 30$ composition produced electrical conductivity of $0.041 \mathrm{~S} / \mathrm{m}$. This suggested that the greater the carbon

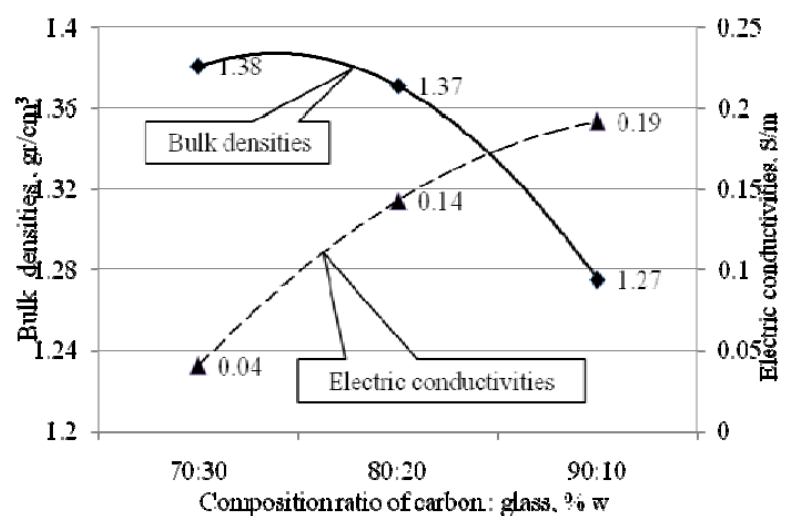

Fig. 2 Relationships the density and electrical conductivity.

content will produce the higher electrical conductivity. This analysis also showed that the glass powder does not produced electrical conductivity, this meant the resistance or non-conductive electrical.

Bulk density carbon-glass composite was tested by following the ASTM D792 standard. Bulk density of the composite test results showed that the higher the carbon content proved also lighter. This was consistent with the apparent density of the test material of carbon and glass, which showed the carbon was lighter than glass. Composite with a composition ratio of 90:10 produced bulk density of $1.27 \mathrm{~g} / \mathrm{cm}^{3}$, while the composite with a composition ratio of 70:30 produced bulk density of $1.38 \mathrm{~g} / \mathrm{cm}^{3}$. Fig. 2 also showed that although with a lower density, for the 90:10 composition, produced high conductivity. This suggested that in addition to lighter composites can also produced a high electrical conductivity. Carbon has been showing good electrical conductivity, carbon-based materials such as graphite, the carbon fiber has been largely used as a conductive phase in composite materials [10]. Electrical conductivity of carbon composites depends mainly on the volume fraction of powder, and a minimum content of carbon powder, carbon powder networking concatenated. The determinants are: conductivity of the powder, volume fraction and the powder characteristics, such as size, shape, surface area, distribution and orientation of filler powder [11]. When a conductive powder was isolated in the insulating polymer, composite conductivity 


\section{Composite}

changed only slightly. When a conductive powder toward each other, electrons can penetrate thin gap $(<$ $10 \mathrm{~nm}$ ) between the powder, which is commonly used conductive filler such as carbon black and graphite flake [12]. Measurement of electrical resistance of carbon fiber polymer matrix composites showed electrical conductivity of 0.001 to $20(\Omega \cdot \mathrm{mm})^{-1}$ [13]. Study of the electrical conductivity of carbon powder produced electrical conductivity of 0.1 to $400 \mathrm{~S} / \mathrm{cm}$. Electrical conductivity values are influenced by the level density carbon-carbon composites [14].

\subsection{Influence of the Density to Wear Rate of Carbon-Glass Composite}

Relationships of the wear rate on the density of the composite is shown in Fig. 3. Increase of wear rate was followed by a decrease in density. This suggested that the lighter the composite, the higher the rate of wear. Increase in the content of the carbon powder will make the lighter the composite, but also makes the softer the composite, so that the higher the wear rate. Composites of carbon-glass with the composition ratio of 70:30 showed the density of $1.38 \mathrm{~g} / \mathrm{cm}^{3}$, resulting wear rate 6.86738E-06 $\mathrm{mm}^{3} / \mathrm{Nm}$. The composite was hard, but heavy. While the composite of carbon-glass with the composition ratio of 90:10 showed density of $1.27 \mathrm{~g} / \mathrm{cm}^{3}$, resulting wear rate $8.67425 \mathrm{E}-06 \mathrm{~mm}^{3} / \mathrm{Nm}$. The composite was lighter, but soft.

Wear resistance showed good correlation with other mechanical properties [15], for example hardness. Tribology properties of composite made of carbon was

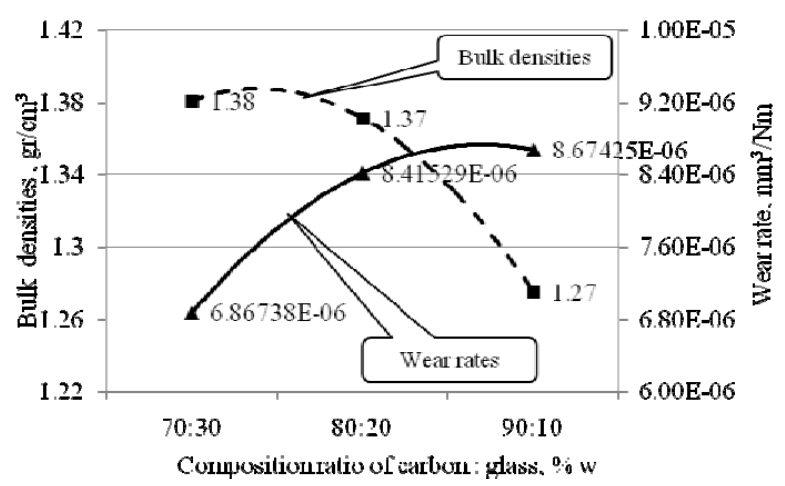

Fig. 3 Relationships between the density and rate of wear. affected by the humidity factor in work wear, microstructure, fabrication processes, all of which affected the performance of the composite wear resistance [16]. Matrix surrounding the carbon powder could change the frictional properties. Specimen powders chipped were a major cause the increased rate of wear. Wear rate is strongly affected by oxidation, the higher the temperature of friction accelerates wear by oxidation [17]. During friction testing operations in this study, estimated fractions of carbon or glass powder spread on the contact of the surface friction. Wear powder were left on the friction between the surface and in the surface roughness or voids, or porosity of the surface [18], then the wear debris powder contributed to the friction abrasion process. Wear parameters (load, sliding speed or friction) environment (temperature, humidity) and surface conditions influenced the composite friction wear and friction properties of the composite [19]. Interface bonding properties of powder/matrix was highly dependent on the nature of the surface (topology and the surface chemistry) of powder reinforcement. One of the prerequisites good adhesion between the powder and the matrix were that the surface energy of carbon powder should be higher or equal to the surface energy of matrix [20].

\subsection{Relationship of the Wear Rate on Electric Conductivity of the Carbon-Glass Composite}

Pantograph collector strip works with friction against the wire of the power train overhead while delivering an electric current. Fig. 4 shows that the

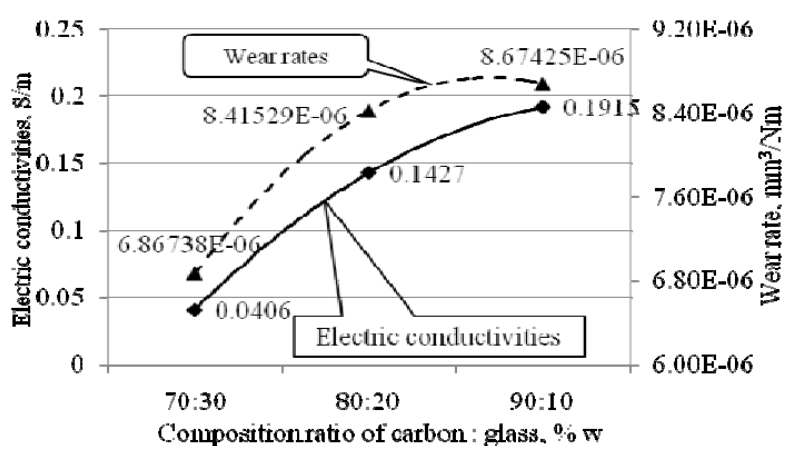

Fig. 4 The relationship between electrical conductivity and wear rate. 
higher the electrical conductivity the higher rate of wear. Composites of carbon-glass with the composition ratio of 70:30 showed electrical conductivity of $0.0406 \mathrm{~S} / \mathrm{m}$ and the wear rate of $6.86738 \mathrm{E}-06 \mathrm{~mm}^{3} / \mathrm{Nm}$. Meanwhile, the composite of carbon - glass with the composition ratio of 90:10 showed electrical conductivity of $0.1915 \mathrm{~S} / \mathrm{m}$ and the wear rate of $8.67425 \mathrm{E}-06 \mathrm{~mm}^{3} / \mathrm{Nm}$.

The higher the carbon content the higher the electrical conductivity, but the higher the wear rate, it indicated the composite increasingly softened.

\subsection{Map of Element Distribution of the Composite} Content

Test of SEM EDS and mapping was performed with JEOL SEM testing machine. Microstructure of the composite of carbon-glass of the composition ratio of 70:30 is shown in Fig. 5.

Microstructure of the bulk composite shows the distribution of the glass powder which is relatively evenly distributed, in the micro-images are shown with the distribution of white shiny granules. While the black grain distribution shows the distribution of carbon in the composite bulk. EDS testing is shown in Fig. 6.

Analysis of the content of the element in the composite of carbon-glass is shown in Table 1. Results of analysis of composite bulk at 70:30 composition showed carbon content of $68.23 \%$ weight, and oxygen $23.23 \%$, while the glass powder was indicated by the silica content of $5.13 \%$, Sodium $1.3 \%$, Calcium $1.61 \%$, and potassium $0.5 \%$ weighting.

Distribution of each element contained in the composite is shown in Fig. 7. Each element contained in the composite was distributed relatively evenly. Fig. 7a shows the distribution of carbon in the composite, the picture shows the evenly distribution of the carbon adjacent to the other elements. Fig. 7b shows the distribution of the oxygen elements, spread relatively evenly adjacent to the other elements. Fig. 7c shows the distribution of the elements sodium, distributed evenly adjacent to the other elements. Fig. $7 \mathrm{~d}$ shows the distribution of the element silica which is one of the inherent elements of glass powder. Similarly, the elements potassium and calcium which is also an element carried by the glass powder distributed evenly in the mixture of carbon-glass composite, as shown in Figs. $7 \mathrm{e}$ and $7 \mathrm{f}$.

\section{Conclusions}

Analysis showed that the higher the carbon content

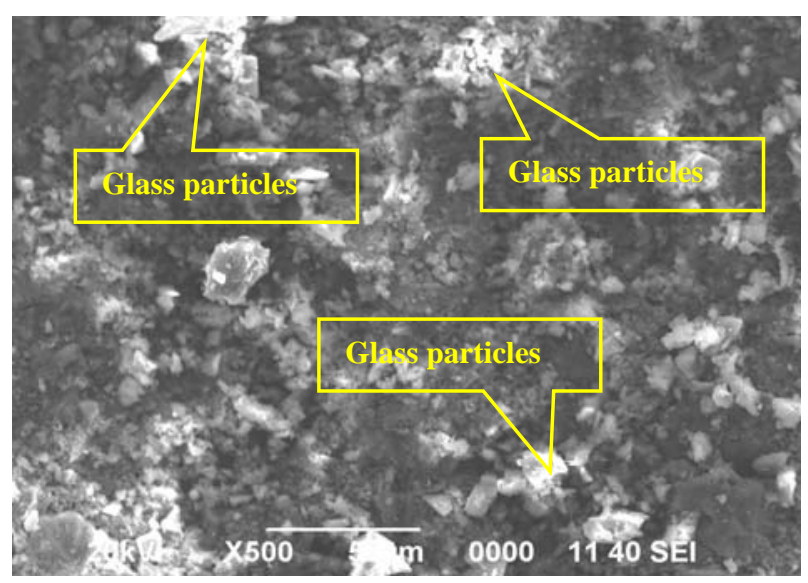

Fig. 5 Bulk composite microstructure.

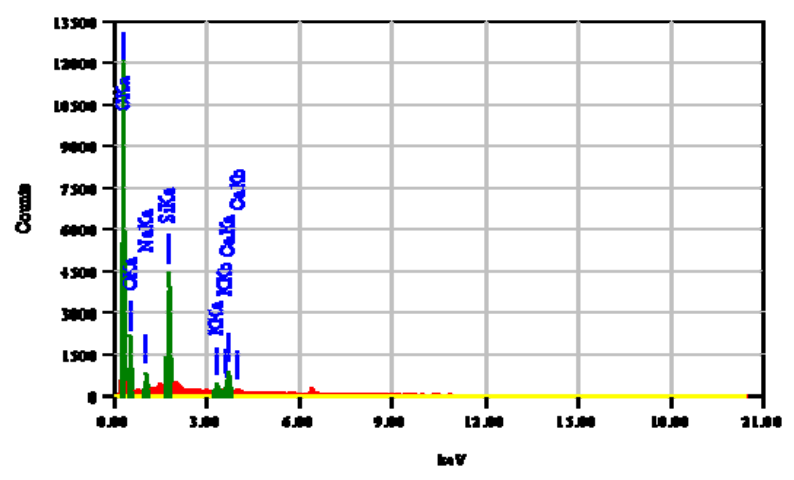

Fig. 6 Elements contained in the composite.

Table 2 Percentage mass of elements in the composite, the composition ratio of 70:30.

\begin{tabular}{ll}
\hline Elements & Mass (\%) \\
\hline $\mathrm{C}$ & 68.23 \\
$\mathrm{O}$ & 23.23 \\
$\mathrm{Na}$ & 1.30 \\
$\mathrm{Si}$ & 5.13 \\
$\mathrm{~K}$ & 0.50 \\
$\mathrm{Ca}$ & 1.61 \\
Total & 100 \\
\hline
\end{tabular}




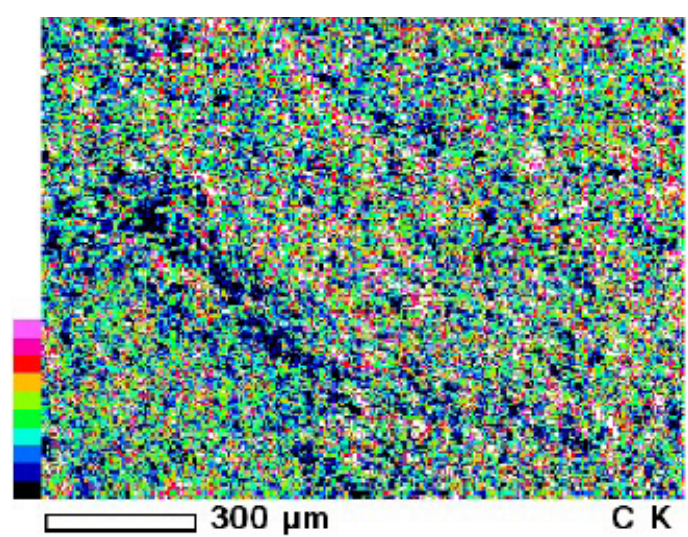

(a)

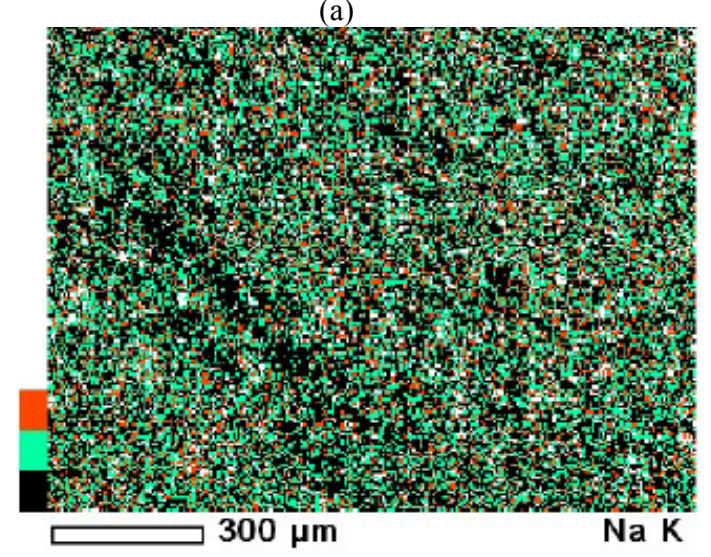

(c)

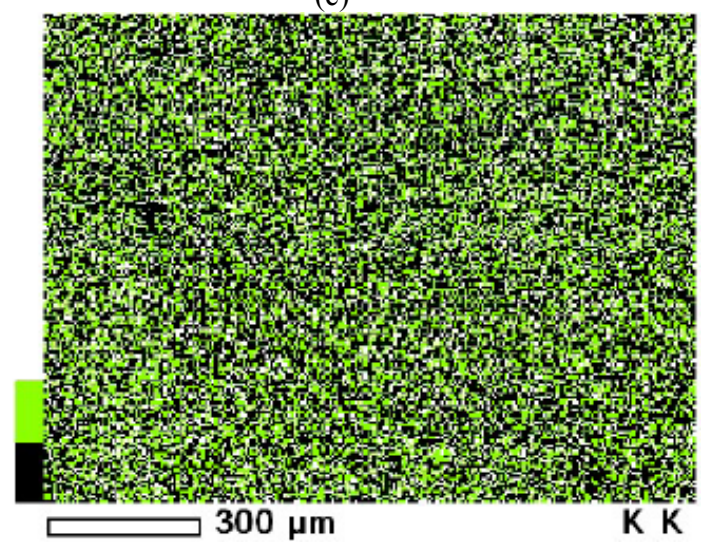

(e)

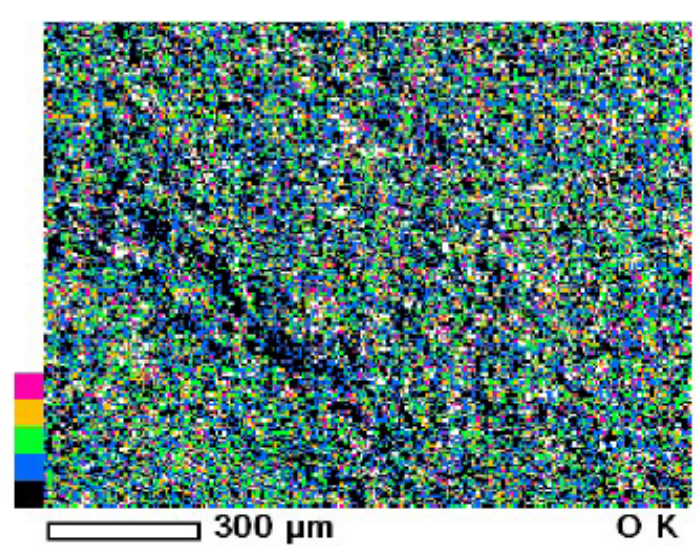

(b)

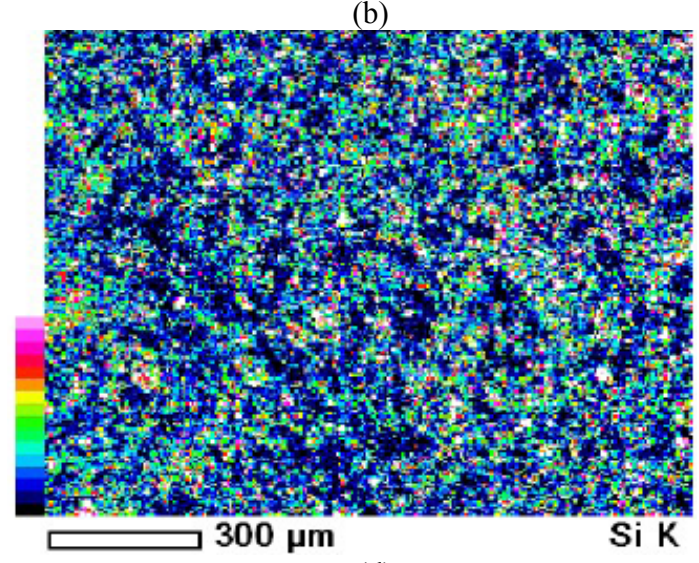

(d)

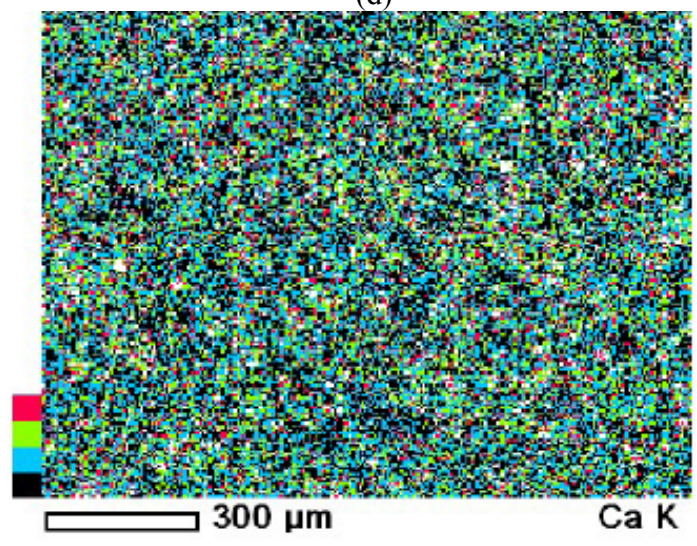

(f)

Fig. 7 Map of the distribution of elements in the composite bulk, composition ratio of 70:30.

will result in higher electrical conductivity, but also shows that this composite lightweight. Increased carbon content will make the composite lightweight, but also makes the soft composite, so that the higher the wear rate.

Glass powder useful to restrain the rate of wear of composites. Lowest wear rate was indicated by a mixture of carbon-glass composite with a composition ratio of $70: 30$, i.e., $6.86738 \mathrm{E}-06 \mathrm{~mm}^{3} / \mathrm{Nm}$. Carbon powder is softer than glass powder, the highest wear rate was indicated by carbon-glass composite with 90:10 composition, i.e., $8.67425 \mathrm{E}-06 \mathrm{~mm}^{3} / \mathrm{Nm}$.

The content of glass powder caused a low electrical conductivity, carbon-glass composite with a composition ratio of 70:30 showed electrical conductivity of $0.041 \mathrm{~S} / \mathrm{m}$. A high content of carbon 
powder encouraged increased electrical conductivity of the composite. Mixture of carbon-glass composite with the composition ratio of 90:10 produced electrical conductivity of $0.192 \mathrm{~S} / \mathrm{m}$.

\section{Acknowledgments}

The authors wish to thank the directorate of research and community service, the directorate general of higher education, ministry of education and culture of the Republic of Indonesia for funding this research work.

\section{References}

[1] B. Giuseppe, A. Collina, A procedure for the wear prediction of collector strip and contact wire in pantograph-catenary system, Wear 266 (2009) 46-59.

[2] C. Blanco, R. Santamarı, J. Bermejo, R. Menendez, Pitch-based carbon composites with granular reinforcements for frictional applications, Carbon 38 (2000) 1043-1051.

[3] F.H. Su, Z.Z. Zhang, W.M. Liu, Mechanical and tribological properties of carbon fabric composites filled with several nano-particulates, Wear 260 (2006) 861-868.

[4] X. R. Zhang, X.Q. Pei, Q.H. Wang, The effect of fiber oxidation on the friction and wear behaviors of short-cut carbon fiber/polyimide composites, EXPRESS Polymer Letters 1 (5) (2007) 318-325.

[5] H.K. Shin, H.B. Lee, K.S. Kim, Tribological properties of pitch-based 2-D carbon-carbon composites, Carbon 39 (2001) 959-970.

[6] P.A. Edy, A. Zulfia, J.W. Soedarsono, Wear properties of carbon-carbon composites processed by hot press (HP) based on coal waste powder, Journal of Materials Science and Engineering B 1 (2011) 43-47.

[7] P.A., Edy, I. Rebet, S. Ruswanto, A. Zulfia, J.W. Soedarsono, Properties of wear rate of composites made of carbon powder with a matrix of waste glass, Journal of Materials Science and Engineering A 2 (11) (2012) 669-676.

[8] P.A. Edy, A. Zulfia, J.W. Soedarsono, Effect of the density to the electrical conductivity of carbon-carbon composite made of the mixture of organic waste carbon,
Journal of Materials Science and Engineering A 2 (5) (2012) 402-409.

[9] W.M. Salih, S.M. Salih, M.M. Salih, The effect of time variation on the wear sliding behavior of composites, American Journal of Applied Sciences 6 (5) (2009) 1028-1030.

[10] C. Ioana, F. Manea, C. Radovan, A. Pop, G. Burtica, P. Malchev, et al, Carbon-based composite electrodes: Preparation, characterization and application in electroanalysis, Sensors 7 (2007) 2626-2635.

[11] K. Kyriaki, H. Fukushima, L.T. Drzal, A route for polymer nanocomposites with engineered electrical conductivity and percolation threshold, Materials 3 (2010) 1089-1103.

[12] S. Erol, L, Bai, Electrically conductive epoxy adhesives, Polymers 3 (2011) 427-466.

[13] L.X. Shen, J. Li, B.M. Liaw, F. Delale, J.H. Chung, Modeling and analysis of the electrical resistance measurement of carbon fiber polymer-matrix composites, Composites Science and Technology $67 \quad$ (2007) 2513-2520.

[14] A. Celzard, J.F. Mareche, F. Payot, G. Furdin, Electrical conductivity of carbonaceous powders, Carbon 40 (2002) 2801-2815.

[15] L. Evgenii, V. Kurbatkina, Z. Alexandr, Improved mechanical and tribological properties of metal-matrix composites dispersion-strengthened by nanoparticles, Materials 3 (2010) 97-109.

[16] N.H. Tai, H.H. Kuo, J.H. Lin, C.P. Ju, Mechanical and tribological properties of 2-D carbon/carbon composites densified through pulse chemical vapor infiltration, Journal of Materials Science 37 (2002) 3693-3703.

[17] H.K. Shin, H.B. Lee, K.S. Kim, Tribological properties of pitch-based 2-D carbon-carbon composites, Carbon 39 (2001) 959-970.

[18] C. Blanco, J. Bermejo, H. Marsh, R. Menendez, Chemical and physical properties of carbon as related to brake performance, Wear 213 (1997) 1-12.

[19] S.J. Park, M.K. Seo, J.R. Lee, Effect of oxidation inhibitor on the low energy tribological behavior of carbon-carbon composites, Carbon 40 (2002) 835-843.

[20] H. Dwivedi, R.B. Mathur, T.L. Dhami, O.P. Bahl, M. Monthioux, S.P. Sharma, Evidence for the benefit of adding a carbon interphase in an all-carbon composite, Carbon 44 (2006) 699-709. 